\title{
Selection and Adaptation of Saccharomyces cerevisae to Increased Ethanol Tolerance and Production
}

\author{
JAN FIEDUREK*, MARCIN SKOWRONEK and ANNA GROMADA \\ Department of Industrial Microbiology, Maria Curie-Skłodowska University, Lublin, Poland
}

Received 2 August 2010, revised 12 January 2011, accepted 20 January 2011

\begin{abstract}
A total of 24 yeast strains were tested for their capacity to produce ethanol, and of these, 8 were characterized by the best ethanol yields (73.11-81.78\%). The most active mutant Saccharomyces cerevisiae ER-A, resistant to ethanol stress, was characterized by high resistance to acidic ( $\mathrm{pH} 1.0$ and 2.0 ), oxidative $\left(1\right.$ and $2 \%$ of $\left.\mathrm{H}_{2} \mathrm{O}_{2}\right)$, and high temperature $\left(45\right.$ and $\left.52^{\circ} \mathrm{C}\right)$ stresses. During cultivation under all stress conditions, the mutants showed a considerably increased viability ranging widely from about 1.04 to 3.94 -fold in comparison with the parent strain S. cerevisiae ER. At an initial sucrose concentration of $150 \mathrm{~g} / \mathrm{l}$ in basal medium A containing yeast extract and mineral salts, at $30^{\circ} \mathrm{C}$ and within $72 \mathrm{~h}$, the most active strain, $S$. cerevisiae ER-A, reached an ethanol concentration of $80 \mathrm{~g} / 1$, ethanol productivity of $1.1 \mathrm{~g} / \mathrm{l} / \mathrm{h}$, and an ethanol yield (\% of theoretical) of 99.13 . Those values were significantly higher in comparison with parent strain (ethanol concentration $71 \mathrm{~g} / \mathrm{l}$ and productivity of $0,99 \mathrm{~g} / \mathrm{l} / \mathrm{h}$ ). The present study seems to confirm the high effectiveness of selection of ethanolresistant yeast strains by adaptation to high ethanol concentrations, for increased ethanol production.
\end{abstract}

Key words: adaptation to high ethanol concentration, ethanol tolerance, fermentation, yeast

\section{Introduction}

Bio-ethanol production by yeast is a growing industry due to energy and environmental demands (Schubert, 2006). Saccharomyces cerevisiae and related yeast species have been extensively used in fermentation, wine-making, sake-making and brewing processes. Successful performance of alcoholic fermentations, however depends on the ability of the yeast strains used to cope with a number of stress factors occurring during the process (Van Uden, 1985; Viegas et al., 1989; Hirasawa et al., 2007), including osmotic pressure imposed by the initial high sugar concentration and stress induced by fermentation end-products or sub-products such as ethanol or acetate. Among these, the stress induced by increasing amounts of ethanol, accumulating to toxic concentrations during ethanol fermentation, is the major factor responsible for reduced ethanol production yields and, ultimately, for stuck fermentations (Gibson et al., 2007). Thus, yeast strains that can endure stress imposed by high ethanol concentrations are highly desirable. Throughout the years many efforts have been made to characterize the mechanisms underlying ethanol stress tolerance, aiming to increase ethanol productivity (Van Uden, 1985; You et al., 2003; Alper et al., 2006; Hirasawa et al., 2007). To overcome fermentation problems, sophisticated refinements of fermentation processes, involving extractive fermentation (Jones et al., 1993; Da Silva et al., 1999), cell immobilization (de Vasconcelos et al., 2004; Verbelen et al., 2006), and recycling or retention by membranes (Nishiwaki and Dunn, 1998; Wang and Lin, 2010), were employed with a view to obtaining a large quantity of fermenting biomass as well as removing the inhibitory ethanol product. Successful engineering of yeast transcription machinery for this purpose was also reported (Alper et al., 2006).

The present study was conducted to select the best ethanol-producing yeast strains from our collection, to improve yeast fermentation performance by adaptation, and to optimize the conditions for alcohol production from sucrose. There are, to our knowledge, only a few studies that describe the creation of ethanol-tolerant $S$. cerevisiae mutants using adaptation and ethanol stress as the selection pressure (Brown et al., 1982; Remize et al., 1999; Stanley et al., 2010).

\footnotetext{
* Corresponding author: J. Fiedurek, Department of Industrial Microbiology, Maria Curie-Skłodowska University, Akademicka 19, 20-033 Lublin, Poland; phone: +48 81537 59 33; fax: +48 8153759 60; e-mail: janek@poczta.umcs.lublin.pl
} 


\section{Experimental}

\section{Material and Methods}

Microorganisms and media. The strains of the yeast listed in Table I were maintained at $4^{\circ} \mathrm{C}$ on malt agar slants. For inoculum preparation selected strains were cultivated on a growth medium A containing glucose, $2 \%$; bactopepton, $2 \%$ and yeast extract, $1 \%$. Fermentations were performed using a basal medium A containing: sucrose, $15.0 \%$; yeast extract, $1.0 \%$; $\left(\mathrm{NH}_{4}\right)_{2} \mathrm{SO}_{4}, 0.3 \%$ and $\mathrm{KH}_{2} \mathrm{PO}_{4}, 0.1 \%$.

Adaptation for increased ethanol production. Enrichments for increased ethanol production were carried out according to the method of Dinh et al., (2008) with some modifications. The cultivation of the $S$. cerevisiae ER strain was carried out in malt medium containing ethanol and then the culture was transferred to a fresh medium containing the same ethanol concentration. Adapted cultures were grown in culture tubes ( 18 by $150 \mathrm{~mm}$ ) containing $10 \mathrm{ml}$ of that medium and were incubated at $30^{\circ} \mathrm{C}$ without agitation. After that, the culture was transferred to a medium containing a higher ethanol concentration, followed by repetitive cultivations. The initial ethanol concentration was set at $5.0 \%(\mathrm{w} / \mathrm{v})$ and it was changed gradually from 6.0 to $15.0 \%$. New derivatives of $S$. cerevisiae were isolated from the adapted cultures after 10 months of serial transfers into media with high concentrations of ethanol. At the end of this period, two clones were selected for further study; these clones were designated as strain ER-A and ER-M.

The adaptation of the yeast was evaluated by measuring the optical density of the culture at $\mathrm{OD}_{600}$. Viability in ethanol was determined by maintaining yeast cells of $S$. cerevisiae ER in malt medium supplemented with $5-15 \%$ ethanol for $48 \mathrm{~h}$ at $30^{\circ} \mathrm{C}$, plating them on malt agar plate, and subsequently counting the number of colonies formed. Control cultures were maintained in the same medium without ethanol.

Inoculum preparation. For the preparation of inoculum, yeast strains were transferred from agar

Table I

Screening yeast strains for efficient ethanol production

\begin{tabular}{|c|c|c|c|c|c|c|}
\hline \multirow{3}{*}{ Strain } & \multicolumn{6}{|c|}{ Sucrose concentration $(\%)$} \\
\hline & 15 & 40 & 15 & 40 & 15 & 40 \\
\hline & \multicolumn{2}{|c|}{$\begin{array}{c}\text { Catalase activity } \\
(\mathrm{U})\end{array}$} & \multicolumn{2}{|c|}{$\begin{array}{l}\text { Ethanol } \\
(\% \mathrm{w} / \mathrm{v})^{\mathrm{a}}\end{array}$} & \multicolumn{2}{|c|}{$\begin{array}{c}\text { Ethanol yield } \\
\text { (\% of theoretical) }\end{array}$} \\
\hline Candida shaetaceae ATCC 22-994 & 8.67 & 6.61 & 0.70 & 0.40 & 8.67 & 1.86 \\
\hline Candida utilis CCY 29-38-18 & 8.70 & 7.13 & 2.00 & 0.70 & 24.78 & 3.25 \\
\hline Kluyveromyces fragilis IPF & 8.07 & 10.00 & 5.00 & 3.00 & 61.96 & 13.94 \\
\hline Kluyveromyces marxianus CCY 50-2-1 & 4.38 & 4.69 & 3.10 & 4.30 & 38.41 & 19.98 \\
\hline${ }^{1}$ Saccharomyces bayanus S-21 & 4.25 & 1.89 & 6.60 & 7.60 & 81.78 & 35.32 \\
\hline${ }^{1}$ Saccharomyces owiformis & 3.78 & 5.34 & 6.00 & 7.00 & 74.35 & 32.53 \\
\hline${ }^{2}$ Saccharomyces carlsbergensis FD & 4.31 & 4.48 & 6.48 & 6.49 & 80.30 & 30.16 \\
\hline${ }^{3}$ Saccharomyces cerevisiae Anker & 2.58 & 6.03 & 5.80 & 8.10 & 71.87 & 37.64 \\
\hline Saccharomyces cerevisiae A364A & 1.83 & 2.08 & 3.80 & 2.80 & 47.09 & 13.01 \\
\hline Saccharomyces cerevisiae DBY 747 & 6.81 & 6.64 & 6.40 & 6.80 & 79.30 & 31.60 \\
\hline${ }^{4}$ Saccharomyces cerevisiae ER & 3.78 & 3.08 & 6.60 & 9.75 & 81.78 & 45.31 \\
\hline${ }^{4}$ Saccharomyces cerevisiae GM & 5.20 & 9.04 & 5.80 & 6.00 & 71.87 & 27.88 \\
\hline${ }^{3}$ Saccharomyces cerevisiae Hammer & 3.22 & 6.75 & 5.80 & 9.20 & 71.87 & 42.75 \\
\hline${ }^{1}$ Saccharomyces cerevisiae JA & 8.41 & 5.34 & 5.90 & 7.20 & 73.11 & 33.46 \\
\hline${ }^{2}$ Saccharomyces cerevisiae PG & 4.06 & 5.09 & 6.00 & 6.80 & 74.35 & 31.60 \\
\hline${ }^{1}$ Saccharomyces cerevisiae $\mathrm{J}$ & 5.81 & 4.84 & 1.10 & 2.40 & 13.63 & 11.15 \\
\hline${ }^{1}$ Saccharomyces elipsoideus Sz.o. & 3.81 & 4.29 & 6.48 & 5.64 & 80.30 & 26.21 \\
\hline Saccharomyces fragilis II 11 & 4.71 & 4.90 & 5.00 & 2.20 & 61.96 & 10.22 \\
\hline Saccharomyces fragilis $11-54$ & 9.07 & 7.72 & 3.80 & 6.20 & 47.09 & 28.81 \\
\hline Saccharomyces fragilis S-24 & 9.84 & 5.91 & 3.10 & 3.20 & 38.41 & 14.87 \\
\hline Saccharomyces fragilis $\mathrm{S}-25$ & 6.88 & 8.05 & 5.10 & 6.20 & 63.20 & 28.81 \\
\hline${ }^{1}$ Saccharomyces mellis 1 & 3.71 & 3.78 & 0.70 & 0.80 & 8.67 & 3.72 \\
\hline Saccharomyces muciparus CCM 21-25-1 & 8.54 & 7.72 & 4.10 & 3.00 & 50.80 & 13.94 \\
\hline${ }^{1}$ Saccharomyces rouxii & 7.53 & 8.71 & 0.60 & 0.20 & 7.43 & 0.93 \\
\hline
\end{tabular}

The strains were incubated in $50 \mathrm{ml}$ conical flasks, each containing $20 \mathrm{ml}$ of basal medium A containing $15 \%$ or $40 \%$ of sucrose during $72 \mathrm{~h}$.

a Values are averages of 3 replicate determinations with standard deviations of $< \pm 5 \%$

${ }^{1}$ Wine yeasts; ${ }^{2}$ Brewing yeasts; ${ }^{3}$ Baker's yeast; ${ }^{4}$ Distillery yeast 
slants into 50-ml Erlenmeyer flasks containing $10 \mathrm{ml}$ of sterile liquid growth medium A, which were cultured at $30^{\circ} \mathrm{C}$ on a rotary shaker (Shaker Orbit The LAB-LINE Instruments Inc, Melrose Park, Illinois, USA) at $150 \mathrm{rpm}$ for $24 \mathrm{~h}$.

Ethanol fermentations. Fermentations with the selected strain were conducted in 300-ml Erlenmeyer flasks containing $100 \mathrm{ml}$ of basal medium A (pH 5.5). The flasks were inoculated with $10 \% \mathrm{v} / \mathrm{v}$ seed culture. Fermentations were carried out for $72 \mathrm{~h}$ at $30^{\circ} \mathrm{C}$ (if not indicated otherwise) in a shaker at $90 \mathrm{rpm}$. Ethanol evaporation was prevented by rubber stoppers, with fermentative tubes filled with $50 \% \mathrm{H}_{2} \mathrm{SO}_{4}$. The fermentation parameters were corrected by ethanol, sucrose and biomass withdrawn during sampling. Overall biomass as well as ethanol yields and sucrose consumption were calculated from end-of-batch data, where the peak ethanol concentration was recorded. Other methodological details are given in tables and figures.

Assays. Biomass was estimated from optical density at $600 \mathrm{~nm}$. Dry mass was calculated by referring to a standard curve of cell mass versus absorbance (Hughest et al., 1984). Ethanol was quantified using the Gonchar et al. (2001) method in own modification using o-dianisidine instead of 3,3,5,5'-tetramethylbenzidine (TMB) as chromogen.

Extracellular catalase activity was measured spectrophotometrically by observing the decrease in light absorption at $525 \mathrm{~nm}$ during decomposition of $\mathrm{H}_{2} \mathrm{O}_{2}$ by the enzyme (Fiedurek and Gromada, 1997). One unit $(\mathrm{U})$ of catalase activity was defined as the amount of enzyme catalysing the decomposition of $1 \mu \mathrm{mol}$ hydrogen peroxide per min at $30^{\circ} \mathrm{C}$. Fermentations were performed in 2 replicate cultures, and analyses were carried out in duplicate. The data given here are the averages of the measurements.

Measurement of respiration. Cell suspensions, prepared as described above, were used to measure the rate of yeast respiration at various medium $\mathrm{pH}$, either in the absence or in the presence of ethanol. Other methodological details are given in the tables and figures. Oxygen concentration in the culture medium was measured by a polarographic dissolved oxygen sensor (Ingold, CH Industrie Nord, Urdorf, Switzerland). The readings were expressed as percentage of the initial level of saturation $(100 \%)$.

\section{Results}

Production of ethanol during fermentation is limited by the inability of yeast to grow at high ethanol levels, which is why a great deal of effort has been devoted to creating yeast strains that would tolerate high ethanol levels, and be able to continue the fermentation to produce higher concentrations of alcohol.
The development of such strains would have the major advantage of saving the energy involved in distilling and refining ethanol.

A total of 24 yeast strains were tested for their capacity to produce ethanol, and of these, 8 were characterized by the best ethanol yields (73.11-81.78\%). Ethanol production, catalase activity, and ethanol yield were monitored on synthetic medium A. The effects of increasing sucrose concentration from 15 to $40 \%$ on ethanol yield, catalase activity and biomass of the yeast strains were examined. Along with the increase in sucrose concentration from 15 to $40 \%$, a decrease in biomass and ethanol yield was observed. On the other hand, the increase enhanced extracellular catalase production, probably as an effect of stress conditions. Among the 24 strains, 13 (54.2\%) were characterized by high catalase activity when grown on a medium with a high sucrose concentration (40\%) (Table I). The increase in sucrose concentration in the medium (from 15 to $40 \%$ ) caused a significant (1.02 to 3 -fold) reduction in biomass production.

For further selection an industrial strain of $\mathrm{Sac}$ charomyces cerevisiae ER characterized by high ethanol tolerance, higher cell viability especially during "very high gravity" fermentation, and working under a wide range of temperatures $\left(35-40^{\circ} \mathrm{C}\right)$ was used. This strain was used for preparation of inocula for adaptation with high concentrations of ethanol (5 to $15 \%$ ) in order to select ethanol-tolerant yeast. New derivatives of $S$. cerevisiae were isolated from adapted cultures after 10 months of serial transfers. During this period about 120 subsequent transfers were performed. At the end of this period, a two clones were selected from enrichment for further study; those clones, designated as strain $S$. cerevisiae: ER-A and ER-M, were able to grown at $15 \%$ of ethanol in the medium (data not shown). When subjected to a stepwise increase in ethanol concentration with repetitive cultivations, the yeast cells $S$. cerevisiae ER-A adapted to the high ethanol concentration showed better biomass accumulation in the medium containing the same ethanol concentration, in comparison to the cells of the parent strain (Table II). This strain was used for further study.

The most active mutant, $S$. cerevisiae ER-A, resistant to ethanol stress, was characterized by high resistance to acidic ( $\mathrm{pH} 1.0$ and 2.0), oxidative (1 and $2 \%$ of $\left.\mathrm{H}_{2} \mathrm{O}_{2}\right)$ and high temperature $\left(45\right.$ and $\left.52^{\circ} \mathrm{C}\right)$ stresses. The viability of mutants during cultivation under all the mentioned stress conditions increased about 1.04 to 3,94-fold in comparison with the parent strain S. cerevisiae ER. It is worth noting, that mutant of S. cerevisiae ER-A resistant to ethanol stress, generally showed a better adaptation to higher ethanol concentration, as expressed by the increased (about 4-fold) viability at $20 \%$ of ethanol in comparison to its $10 \%$ 
Table II

Effect of ethanol concentration on biomass production

\begin{tabular}{|c|c|c|c|c|}
\hline \multirow{2}{*}{$\begin{array}{c}\text { Ethanol } \\
(\% \mathrm{w} / \mathrm{v})\end{array}$} & \multicolumn{2}{|c|}{$\begin{array}{c}\text { Dry matter } \\
(\mathrm{g} / \mathrm{l})^{\mathrm{a}} \text { after }\end{array}$} & \multicolumn{2}{c|}{$\begin{array}{c}\text { Relative to } \\
\text { the parent-type (-fold) }\end{array}$} \\
\cline { 2 - 5 } & $24 \mathrm{~h}$ & $48 \mathrm{~h}$ & $24 \mathrm{~h}$ & $48 \mathrm{~h}$ \\
\hline \multicolumn{5}{|c|}{ Saccharomyces cerevisiae ER (parent) } \\
\hline Control (none) & 2.33 & 3.04 & \\
\hline 11 & 1.10 & 1.67 & \\
\hline 12 & 0.58 & 1.11 & \\
\hline 13 & 0.41 & 0.63 & \\
\hline 14 & & & \\
\hline 15 & 0.19 & 0.22 & 1.00 \\
\hline \multicolumn{5}{|c|}{ Saccharomyces cerevisiae ER-A } \\
\hline Control (none) & 2.42 & 2.74 & 1.04 & 0.90 \\
\hline 11 & 1.35 & 1.67 & 1.23 & 1.00 \\
\hline 12 & 0.65 & 1.24 & 1.12 & 1.12 \\
\hline 13 & 0.53 & 0.87 & 1.29 & 1.38 \\
\hline 14 & 0.44 & 0.77 & 1.42 & 1.64 \\
\hline 15 & 0.30 & 0.36 & 1.58 & 1.64 \\
\hline
\end{tabular}

The strains were incubated in $50 \mathrm{ml}$ conical flasks, each containing $20 \mathrm{ml}$ of basal medium A with ethanol (11-15\%) during 24-48 h.

${ }^{a}$ Values are averages of 6 replicate determinations with standard deviations of $< \pm 6 \%$

\section{Table III}

Effect of abiotic stresses on surviving cells of Saccharomyces cerevisiae ER

\begin{tabular}{|l|r|r|c|}
\hline \multirow{2}{*}{\multicolumn{1}{|c|}{ Stress conditions }} & \multicolumn{2}{|c|}{ Surviving cells (\%) } & $\begin{array}{c}\text { Relative } \\
\text { to the wild- } \\
\text { type (-fold) }\end{array}$ \\
\cline { 2 - 3 } & Parent & ER-A & 1.14 \\
\hline Low pH $(2.0)$ & 81.99 & 93.70 & 1.85 \\
\hline Low pH (1.0) & 3.85 & 7.14 & 1.24 \\
\hline Oxidative stress $\left(1 \% \mathrm{H}_{2} \mathrm{O}_{2}\right)$ & 80.90 & 100.0 & 1.34 \\
\hline Oxidative stress $\left(2 \% \mathrm{H}_{2} \mathrm{O}_{2}\right)$ & 72.0 & 96.50 & 1.46 \\
\hline High temperature $\left(45^{\circ} \mathrm{C}\right)$ & 47.59 & 69.85 & 1.64 \\
\hline High temperature $\left(52^{\circ} \mathrm{C}\right)$ & 26.34 & 43.17 & 1.04 \\
\hline Ethanol $(10 \%)$ & 89.25 & 90.37 & 1.28 \\
\hline Ethanol $(15 \%)$ & 61.02 & 77.93 & 3.94 \\
\hline Ethanol $(20 \%)$ & 10.00 & 39.40 & 30 \\
\hline
\end{tabular}

The strains were incubated in $50 \mathrm{ml}$ conical flasks, each containing $20 \mathrm{ml}$ of basal medium during $24 \mathrm{~h}$ of stress conditions. Low $\mathrm{pH}$ media were obtained by adding $0.1 \mathrm{M} \mathrm{HC} 1$.

${ }^{a}$ Values are averages of 4 replicate determinations with standard deviations of $< \pm 4 \%$

concentration (Table III). A similar trend was also observed for oxidative ( 1 and $2 \%$ of $\mathrm{H}_{2} \mathrm{O}_{2}$ ) and high temperature $\left(45\right.$ and $\left.52^{\circ} \mathrm{C}\right)$ stress, when higher numbers of cells survived in more drastic stress conditions.

Measurements of oxygen consumption at $30^{\circ} \mathrm{C}$ and $\mathrm{pH} 4.5$ showed that ethanol inhibited the respiration rate of yeast. In the absence of added ethanol, the oxygen concentration decreased gradually over the first $15 \mathrm{~min}$ to the level of about $6 \%$. When the experiment was repeated in the presence of $5 \%(\mathrm{w} / \mathrm{v})$ ethanol, the respiration rate of the yeast cells was markedly inhibited, and the oxygen concentration fell more slowly, reaching $10.7 \%$ after $20 \mathrm{~min}$. The higher concentration $(10 \%)$ of ethanol significantly reduced oxygen consumption; in these conditions, more than half of the initial dissolved oxygen content remained

Table IV

Effect of externally added ethanol at concentration $0-15 \%$ on $\mathrm{CO}_{2}$ and biomass production by parent and adapted strain of Saccharomyces cerevisiae MR-A

\begin{tabular}{|c|c|c|c|}
\hline \multirow{2}{*}{$\begin{array}{c}\text { Ethanol } \\
(\% \mathrm{w} / \mathrm{v})\end{array}$} & \begin{tabular}{c} 
Relative metabolic rate $(\%)^{\mathrm{a}, \mathrm{b}}$ \\
Mixing \\
\cline { 2 - 4 }
\end{tabular} & $\begin{array}{c}\text { Mixing } \\
(180 \mathrm{rpm})\end{array}$ & $\begin{array}{c}\text { Dry matter } \\
(\mathrm{g} / \mathrm{l})^{\mathrm{b}}\end{array}$ \\
\hline \multicolumn{3}{|c|}{ Saccharomyces cerevisiae ER (parent) } \\
\hline Control (none) & 39.13 & 73.90 & 2.33 \\
\hline 5 & 21.74 & 39.13 & 1.73 \\
\hline 10 & 4.35 & 4.35 & 1.36 \\
\hline 11 & 0 & 4.30 & 1.10 \\
\hline 12 & 0 & 0 & 0.58 \\
\hline 13 & 0 & 0 & 0.39 \\
\hline 14 & 0 & 0 & 0.28 \\
\hline 15 & 0 & 0 & 0.19 \\
\hline \multicolumn{5}{|c|}{ Saccharomyces cerevisiae ER-A } \\
\hline Control (none) & 43.48 & 100.00 & 2.46 \\
\hline 5 & 30.43 & 52.17 & 2.25 \\
\hline 10 & 5.43 & 13.44 & 1.50 \\
\hline 11 & 4.43 & 13.00 & 1.35 \\
\hline 12 & 0 & 4.35 & 0.70 \\
\hline 13 & 0 & 0 & 0.53 \\
\hline 14 & 0 & 0 & 0.44 \\
\hline 15 & 0 & 0 & 0.34 \\
\hline
\end{tabular}

${ }^{\text {a }}$ Relative metabolic rate (\%) was calculated by counting the number of bubbles of $\mathrm{CO}_{2}$ released from fermentative tubes during $60 \mathrm{~min}$. Maximal amount of bubbles formed during culture of the adapted strain ERA was defined as $100 \%$. The strains were incubated in $50 \mathrm{ml}$ conical flasks, each containing $20 \mathrm{ml}$ of basal medium A with ethanol (5-15\%) during $24 \mathrm{~h}$

${ }^{\mathrm{b}}$ Values are averages of 6 replicate determinations with standard deviations of $< \pm 5 \%$

Table V

Effect of $\left(\mathrm{NH}_{4}\right)_{2} \mathrm{SO}_{4}$ concentration on ethanol production

\begin{tabular}{|c|c|c|c|}
\hline Medium & $\begin{array}{c}\text { Ethanol } \\
(\% \mathrm{w} / \mathrm{v})\end{array}$ & $\begin{array}{c}\text { Ethanol yield } \\
(\% \text { of } \\
\text { theoretical })\end{array}$ & $\begin{array}{c}\text { Dry } \\
\text { matter } \\
(\mathrm{g} / \mathrm{l})\end{array}$ \\
\hline \multicolumn{2}{|c|}{ Saccharomyces cerevisiae ER (parent) } \\
\hline Basal medium A & 6.30 & 78.06 & 5.38 \\
\hline $\begin{array}{l}\text { Modified basal medium A } \\
\text { with }\left(\mathrm{NH}_{4}\right)_{2} \mathrm{SO}_{4}-1,0 \%\end{array}$ & 7.10 & 87.98 & 6.75 \\
\hline \multicolumn{4}{|c|}{ Saccharomyces cerevisiae ER-A $^{\mathrm{a}}$} \\
\hline Basal medium A & 7.20 & 89.22 & 5.04 \\
\hline $\begin{array}{l}\text { Modified basal medium A } \\
\text { with }\left(\mathrm{NH}_{4}\right)_{2} \mathrm{SO}_{4}-1,0 \%\end{array}$ & 8.00 & 99.13 & 6.23 \\
\hline
\end{tabular}

Fermentation conditions: inoculation: $2 \times 10^{7}$ cells $/ \mathrm{ml}$, time fermentation $72 \mathrm{~h}$ at $30^{\circ} \mathrm{C}$ in shaker $90 \mathrm{rpm}$. The strain was incubated in $50 \mathrm{ml}$ conical flasks, each containing $20 \mathrm{ml}$ of basal medium A containing 0.3 and $1.0 \%$ of with $\left(\mathrm{NH}_{4}\right)_{2} \mathrm{SO}_{4}$.

${ }^{a}$ Values are averages of 6 replicate determinations with standard deviations of $< \pm 5 \%$ 


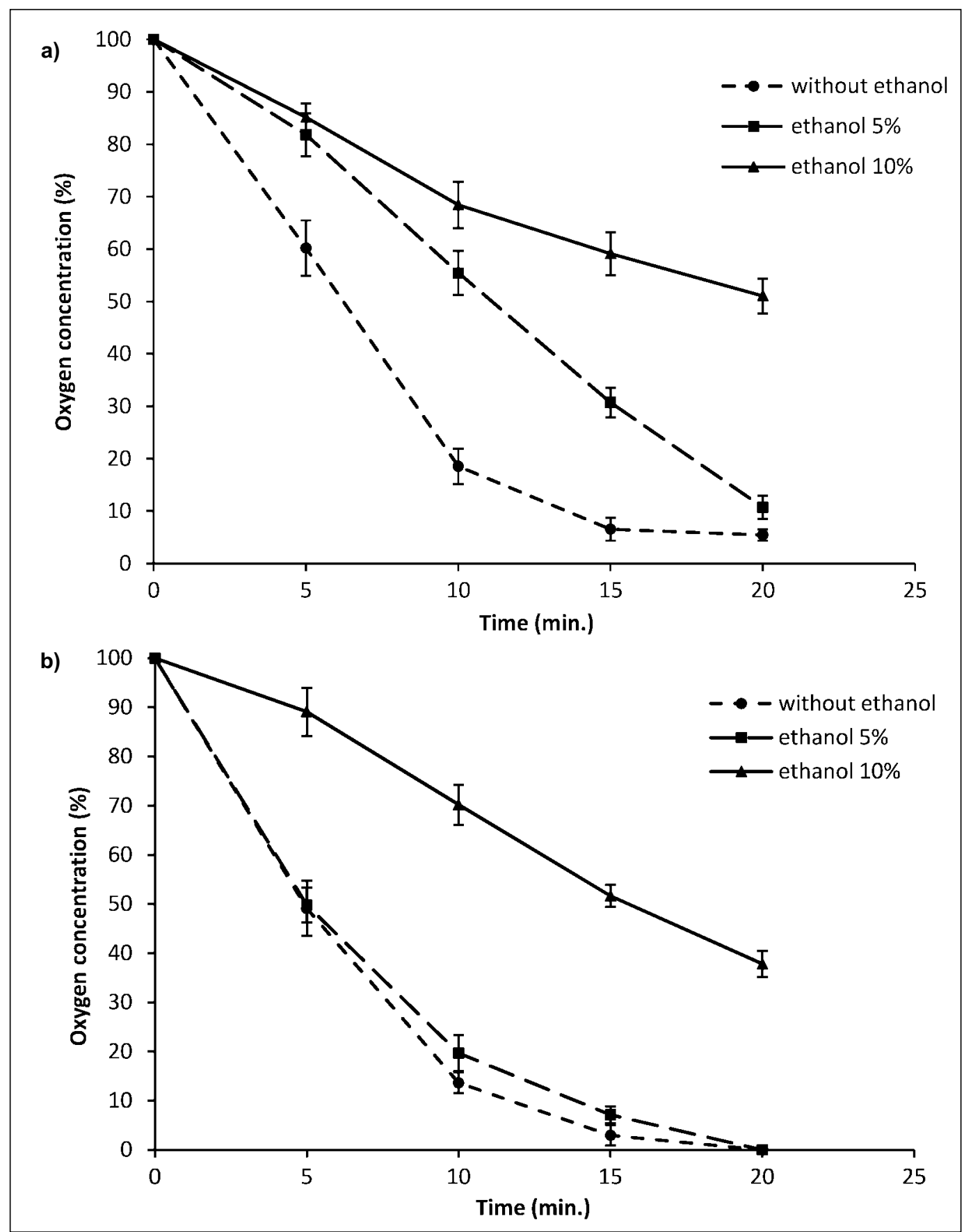

Fig. 1. Effect of ethanol concentration in the medium on the oxygen consumption of Saccharomyces cerevisiae ER strain (a) and Saccharomyces cerevisiae ER-A strain (b).

The values shown represent the mean of three experiments. Error bars represent standard deviations.

in the medium after $20 \mathrm{~min}$ from the beginning of the experiment (Fig. 1a). The adapted cells of $S$. cerevisiae ER-A consumed more oxygen than the parent strain in media with all the tested ethanol concentrations (Fig. 1b). After $20 \mathrm{~min}$ of respiration, the levels of oxygen concentration in media with $5 \%$ and $10 \%$ ethanol were lower by $10.7 \%$ and $13.2 \%$, respectively, as compared with values for the parent strain.

The effect of $5-15 \%$ ethanol externally added to basal medium $\mathrm{A}$ on $\mathrm{CO}_{2}$ production by the parent and the adapted strain of S. cerevisiae ER-A was exam- ined. In comparison with the parent strain, the metabolic activity of adapted cells of $S$. cerevisiae ER-A showed higher resistance to inhibition by ethanol when the cells were grown with 5 and $10 \%(\mathrm{w} / \mathrm{v})$ ethanol. The higher concentration $(11 \%)$ of ethanol completely inhibited metabolic activity of the parent strain when culture was carried out in a shaker at $90 \mathrm{rpm}$, and adapted cells showed insignificant activity in these conditions. Under a higher mixing rate (180 rpm), at $11 \%$ of ethanol, adapted cells of $S$. cerevisiae ER-A were characterized by an about 3 -fold higher 
metabolic activity than the parent strain. A further increase in ethanol concentration in basal medium A to $12 \%$ completely inhibited metabolic activity of the parent strain, and the adapted strain showed very small this activity in these conditions (Table IV).

Table V compares ethanol production by the parental and the mutant strain of $S$. cerevisiae ER-A in basal and modified medium A. The highest ethanol yields for the two strains were obtained on modified medium $\mathrm{A}$, containing $15 \%$ of sucrose, $1 \%$ of yeast extract, $1 \%$ of $\left(\mathrm{NH}_{4}\right)_{2} \mathrm{SO}_{4}$ and $1 \%$ of $\mathrm{KH}_{2} \mathrm{PO}_{4}$, using a very simple fermentation system (shake flask). Considerably better results were achieved for mutant S. cerevisiae ER-A, which was characterized by an ethanol yield of $99.13 \%$ and an ethanol concentration of $8.0 \%$; the respective values for the parental strain were $87.98 \%$ and $7.1 \%$.

\section{Discussion}

Tolerance to high ethanol and sucrose concentrations is an important property of industrial microorganisms. The accumulation of ethanol during cultivation causes stress to yeast cells, leading to a decrease in cell growth and production of target products. Thus, understanding the process of adaptation of yeast to high ethanol concentrations is important as it may lead to the construction of yeast strains able to grow well at high ethanol concentrations. Such ethanol-tolerant yeasts are highly desirable for the production of useful compounds. Improving ethanol tolerance in yeast should, therefore, reduce the impact of ethanol toxicity on fermentation performance (Dinh et al., 2008; Stanley et al., 2010).

Stanley et al. (2010) obtained ethanol-tolerant yeast mutants by subjecting mutagenised and non-mutagenised populations of $S$. cerevisiae W303-1A to adaptive evolution using ethanol stress as a selection pressure. Mutants CM1 (chemically mutagenised) and SM1 (spontaneous) had increased acclimation and growth rates when cultivated in sub-lethal ethanol concentrations, and their survivability in lethal ethanol concentrations was considerably improved compared with the parent strain. Those authors suggested that the increased ethanol tolerance of the mutants was due to their elevated glycerol production rates and the potential of these to increase the ratio of oxidised and reduced forms of nicotinamide adenine dinucleotide $\left(\mathrm{NAD}^{+} / \mathrm{NADH}\right)$ in an ethanol-compromised cell, stimulating glycolytic activity.

The viability of the adapted $S$. cerevisiae ER-A was always higher than for the parental strain, for all the stress conditions used (Table III). For example, the viable population (expressed as a percentage of the initial population) of the ER- culture after $24 \mathrm{~h}$ in
$20 \%$ (w/v) ethanol was $39.40 \%$, respectively, compared with $10.0 \%$ for the parent. Similar viability characterized SM1 and CM1 cultures obtained by Stanley et al. (2010) under lethal ethanol stress conditions $(12 \%(\mathrm{w} / \mathrm{v})$ ethanol, after $12 \mathrm{~h})-52 \%$ and $44 \%$, respectively, compared with $5 \%$ for the parent.

Some researchers have analyzed phenomena associated with adaptation of yeast cells to high ethanol concentrations. Lloyd et al. (1993) found that yeast previously grown in the presence of 5\% ethanol could grow in the medium containing $10 \%$ ethanol, whereas yeast inoculated directly into a medium containing $10 \%$ ethanol failed to grow. Ismail and Ali (1971) reported that no increase in the tolerance of yeast to a high ethanol concentration was observed after ten successive transfers to an environment containing a high ethanol concentration. Therefore, it is expected that exposing yeast cells to a stepwise increase in the level of ethanol stress should be effective for obtaining ethanol-tolerant yeast strains.

The results presented above confirmed that an adapted strain resistant to ethanol stress generally showed better adaptation to other stress conditions, as expressed by the increased survival of the mutant of $S$. cerevisiae ER-A during cultivation under acidic (pH 1.0 and 2.0), oxidative ( 1 and $2 \%$ of $\mathrm{H}_{2} \mathrm{O}_{2}$ ), and high temperature $\left(45\right.$ and $\left.52^{\circ} \mathrm{C}\right)$ stresses. It is worth noting that in the more drastic stress conditions, the ethanol-tolerant mutant was characterized by a higher survival rate. This is in accordance with data presented by Ogawa et al. (2000), who showed that several genes were highly expressed only in the ethanol-tolerant mutant but not in the parent strain. The ethanol-tolerant mutant also exhibited resistance to other stresses including heat, high osmolarity, and oxidative stress in addition to ethanol tolerance. These results indicate that the mutant exhibits multiple stress tolerances due to elevated expression of stress-responsive genes, resulting in accumulation of high amounts of stress protective substances such as catalase, glycerol, and trehalose (Ogawa et al., 2000). The ability of one stress condition to provide protection against other stresses is referred to as cross-protection. Several studies have shown that adaptation to acid stress confers resistance to a wide range of stress conditions including heat, salt, crystal violet, and polymyxin B (Lee et al., 1995; Bearson et al., 1997). However, adaptation to other stresses does not typically induce significant acid tolerance. This implies that acid exposure may be treated by microorganisms as a more general stress indicator, whereas salt and $\mathrm{H}_{2} \mathrm{O}_{2}$ may be more specific stress signals.

A number of specific selection schemes have been elaborated to improve the biosynthetic capacity of production strains. Thus the acid tolerance of Leuconostoc oenos was examined in cells surviving at $\mathrm{pH}$ 
2.6, which is lower than the acid limit of growth (about $\mathrm{pH}$ 3.0). The acid-resistant mutant L. oenos, was found to be able to grow in acidic media and characterized by a high $\mathrm{H}^{+}-$ATPase activity at low $\mathrm{pH}$. Such strains may be an important part of the technology of modern commercial wine production (Drici-Cachon et al., 1996). Accumulation of a large amounts of metabolic end-products during the fermentation period, especially in case of industrial amino acid fermentation, builds up a high osmotic strength which affects both growth and production. Enhanced l-treonine production by salt tolerant mutants of $E$. coli was achieved (Drici-Cachon et al., 1996). Some mutants have been described in $E$. coli which are more resistant to cell lysis in the presence of ethanol (Fried and Novick 1973; Ingram et al., 1980). In this respect, our results obtained in ethanol production can be compared with data provided by Ortiz-Zamora et al. (2008), who isolated and selected yeast strains from alcoholic fermentations of natural sources. These strains were exposed several times to high concentrations of glucose and ethanol in order to select ethanol- and glucosetolerant yeast; 10 were obtained that adapted best to these conditions. Some of these strains demonstrated the highest adaptation to both ethanol $(5-7 \% \mathrm{w} / \mathrm{v})$ and glucose $(20 \% \mathrm{w} / \mathrm{v})$. The maximum yield obtained was $0.46 \mathrm{~g} / \mathrm{g}(90 \%$ theoretical yield) in a $20-\mathrm{L}$ bioreactor with cane molasses.

Araque et al. (2008) selected thermotolerant yeast strains Saccharomyces cerevisiae for bioethanol production, which were able to grow and ferment glucose in the temperature range $35-45^{\circ} \mathrm{C}$. All the strains grew (in agar plates) at 35 and $40^{\circ} \mathrm{C}$, only two strains grew at $42^{\circ} \mathrm{C}$, and no strain grew at $45^{\circ} \mathrm{C}$. Glucoseto-ethanol conversion yield was between $50 \%$ and $80 \%$ of the theoretical value. The ethanol yields by SSF using the selected strain were higher than those obtained using the control yeast.

The selected strain, S. cerevisiae ER-A, showed an ability to grow and ferment sucrose at ethanol concentrations in the medium of 15 and $12 \%(w / v)$, respectively (Tables II and IV). Its resistance to ethanol, externally added to the medium, was significantly higher than for the parent strain. An increase in the rate of mixing from 90 to $180 \mathrm{rpm}$ correlated with a simultaneous increase in the relative fermentation rate $(\%)$ both for the parent and the adapted strain, probably as an effect of a higher mass transfer. The effect of ethanol on yeast growth and fermentation has been studied by Brown et al. (1981).These authors showed complex kinetics which resulted from both an inhibition of the growth rate itself and also a reduction in cell viability. The growth and viability effects had different inhibition constants. Contrary to our data, ethanol was less inhibitory toward fermentation than toward growth in sake yeast.
Some data suggest that an improvement in ethanol tolerance leads to an increase in both ethanol production rate and the total amount of ethanol produced (Jiménez and Benítez, 1988). The adapted $S$. cerevisiae ER-A reached an ethanol concentration of $80 \mathrm{~g} / \mathrm{l}$, an ethanol productivity of $1.1 \mathrm{~g} / \mathrm{l} / \mathrm{h}$, and an ethanol yield (\% of theoretical) 99.13. Those values were significantly higher in comparison with the parent strain (ethanol concentration of $72.9 \mathrm{~g} / \mathrm{l}$ and productivity of $1,01 \mathrm{~g} / \mathrm{l} / \mathrm{h})$.

The studies presented above seem to confirm the high effectiveness of selection of resistant yeast strains by adaptation to high ethanol concentrations for increased ethanol production. Additionally, better adaptation of these mutants to abiotic stresses can affect yeast growth and ethanol productivity. The advantage gained in direct screening is to reduce in a very specific way the number of cultures isolated from the plates, which would normally require testing of productivity via shake flask cultures. This is a significant contribution to make screening of ethanol-producing yeast more efficient. The ethanol tolerant strain was stable in the subsequent subcultures in the absence of stress during 6 months. It can be concluded from the present results that the adapted strain $S$. cerevisiae ER-A showed, at this stage of our studies, a moderate fermentation activity, which gave reasonable ethanol yields from sucrose. Further improvements to the isolated yeast strain and the growth conditions are necessary to utilize the strain for larger-scale fermentation.

\section{Acknowledgements}

The authors wish to thank Prof. Józef Kur (Department of Microbiology Chemical Faculty, Gdańsk University of Technology, Poland) for supplying yeast strain Saccharomyces cerevisiae ER (Ethanol Red).

This work was financially supported by Research Program BW/BiNoZ/UMCS.

\section{Literature}

Alper H., J. Moxley, E. Nevoigt, G.R. Fink and G. Stephanopoulos. 2006. Engineering yeast transcription machinery for improved ethanol tolerance and production. Science 314: $1565-1568$.

Araque E., C. Parra, M. Rodríguez, J. Freer and J. Baeza. 2008. Selection of thermotolerant yeast strains Saccharomyces cerevisiae for bioethanol production. Enzyme Microb. Technol. 43: 120-123.

Bearson S., B. Bearson and J.W. Foster. 1997. Acid stress responses in enterobacteria. FEMS Microbiol. Lett. 147: 173-180. Brown S.W., S.G. Oliver, D.E.F. Harrison and R.C. Righelato. 1981. Ethanol inhibition of yeast growth and fermentation: Differences in the magnitude and complexity of the effect. J. Appl. Microbiol. Biotechnol. 11: 153-155.

Brown S.W. and S.G. Oliver. 1982. Isolation of ethanol-tolerant mutants of yeast by continuous selection. Eur. J. Appl. Microbiol. Biotechnol. 16: 119-122. 
Da Silva F.L.H., M.I. Rodrigues and F. Maugeri. 1999. Dynamic modeling simulation and optimization of an extractive continuous alcoholic fermentation process. J. Chem. Technol. Biotechnol. 74: $176-182$.

Dinh T.N., K. Nagahisa, T. Hirasawa, C. Furusawa and H. Shimizu. 2008. Adaptation of Saccharomyces cerevisiae cells to high ethanol concentration and changes in fatty acid composition of membrane and cell size. PLoS ONE 3(7):e2623. doi: 10.1371/journal.pone.0002623.

Drici-Cachon Z., J. Guzzo, J.F. Cavin and C. Divies. 1996. Acid tolerance in Leuconostoc oenos. Isolation and characterization of an acid-resistant mutant. Appl. Microbiol. Biotechnol. 44: 785-789.

Fried V.A. and A. Novick. 1973. Organic solvents as probes for the structure and function of the membrane: effects of ethanol on the wild and ethanol resistant mutant of Escherichia coli K-12. J. Bacteriol. 114: 239-248.

Gibson B.R., S.J. Lawrence, J.P. Leclaire, C.D. Powell and K.A. Smart. 2007. Yeast responses to stresses associated with industrial brewery handling. FEMS Microbiol. Rev. 31: 535-69.

Gonchar M.V., M.M. Maidan, H.M. Pavlishko and A. Sibirny. 2001. A new oxidase-peroxidase kit for ethanol assays in alcoholic beverages. Food Technol. Biotechnol. 39: 37-42.

Fiedurek J. and A. Gromada. 1997. Selection of biochemical mutants of Aspergillus niger with enhanced catalase production. Appl. Microb. Biotechnol. 47: 313-316.

Hirasawa T., K. Yoshikawa, Y. Nakakura, K. Nagahisa, C. Furusawa, Y. Katakura, H. Shimizu and S. Shioya. 2007. Identification of target genes conferring ethanol stress tolerance to Saccharomyces cerevisiae based on DNA microarray data analysis. J. Biotechnol. 131: 34-44.

Hughest D.B., N.J. Tudroszen and C.J. Moye. 1984. The effect of temperature on the kinetics of ethanol production by a thermotolerant strain of Kluyveromyces marxianus. Biotechnol. Lett. 6: $1-6$.

Ingram L.O., N.S. Vreeland and L.C. Eaton. 1980. Alcohol tolerance in Escherichia coli: a proposed common mechanism for changes induced by ethanol. Pharmacol. Biochem. Behav. 13: 191-195.

Ismail A.A. and M.M. Ali. 1971. Selection of high ethanol-yielding Saccharomyces I. Ethanol tolerance and the effect of training in Saccharomycess cerevisiae Hansen. Folia Microbiol. 16: 346-369. Jiménez J. and T. Benítez. 1988. Selection of ethanol-tolerant yeast hybrids in pH-regulated continuous culture. Appl. Environ. Microbiol. 54: 917-922.

Jones T.D., J.M. Havard and A.J. Daugulis. 1993. Ethanol production from lactose by extractive fermentation. Biotechnol. Lett. 15: 871-876.
Lee I.S., J. Lin, H.K. Hall, B. Bearson and J.W. Foster. 1995 The stationary-phase sigma factor $\mathrm{s}^{\mathrm{S}}(\mathrm{RpoS})$ is required for a sustained acid tolerance response in virulent Salmonella typhimurium. Mol. Microbiol. 17: 155-167.

Lloyd D., S. Morrell, H.N. Carlsen, H. Degn, P.E. James and C.C. Rowlands. 1993. Effects of growth with ethanol on fermentation and membrane fluidity of Saccharomyces cerevisiae. Yeast 9: 825-833.

Nishiwaki A. and I.J. Dunn. 1998. Analysis of a two-stage fermentor with recycle for continuous ethanol production. Chem. Eng. Commun. 168: 207-227.

Ogawa Y., A. Nitta, H. Uchiyama, I. Takesh, H. Shimoi and K. Ito. 2000. Tolerance mechanism of the ethanol-tolerant mutant of sake yeast. J. Biosc. Bioeng. 90: 313-320.

Ortiz-Zamora O., R. Cortés-García, M. Ramírez-Lepe, J. Gómez-Rodríguez and M.G. Aguilar-Uscanga. 2008. Isolation and selection of ethanol-resistant and osmotolerant yeasts from regional agricultural sources in Mexico. J. Food. Process. Engin. 32: 775-786.

Remize F., J.L. Roustan, J.M. Sablayrolles, P. Barre P and S. Dequin. 1999. Glycerol overproduction by engineered Saccharomyces cerevisiae wine yeast strains leads to substantial changes in by-product formation and to a stimulation of fermentation rate in stationary phase. Appl. Environ. Microbiol. 65: 143-149.

Schubert C. 2006. Can biofuels finally take center stage? Nat. Biotechnol. 24: 777-784.

Stanley D., S. Fraser, P.J. Chambers, P. Rogers and G.A. Stanley. 2010. Generation and characterisation of stable ethanol-tolerant mutants of Saccharomyces cerevisiae. J. Ind. Microbiol. Biotechnol. 37: 139-149.

Van Uden N. 1985. Ethanol toxicity and ethanol tolerance in yeasts. Ann. Rep. Ferm. Process. 8: 11-58.

de Vasconcelos J.N., C.E. Lopes and F.P. de Franca. 2004. Continuous ethanol production using yeast immobilized on sugar-cane stalks. Braz. J. Chem. Eng. 21: 357-365.

Verbelen P.J., D.P. De Schutter, F. Delvaux, K.J. Verstrepen and F.R. Delvaux. 2006. Immobilized yeast cell systems for continuous fermentation applications. Biotechnol. Lett. 28: 1515-1525. Viegas C.A., M.F. Rosa, I. Sa-Correia and J.M. Novais. 1989. Inhibition of yeast growth by octanoic and decanoic acids produced during ethanolic fermentation. Appl. Environ. Microbiol. 55: 21-28.

Wang F.S. and H.T. Lin. 2010. Fuzzy optimization of continuous fermentations with cell recycling for ethanol production. Ind. Eng. Chem. Res. 49: 2306-2311.

You K.M., C.L. Rosenfield and D.C. Knipple. 2003. Ethanol tolerance in the yeast Saccharomyces cerevisiae is dependent on cellular oleic acid content. Appl. Environ. Microbiol. 69: 1499-503. 